\title{
Métodos inmunológicos para la detección de cambios en el sistema dopaminérgico: western blot y neurohistología para la detección de DARPP-32
}

\author{
SERGIO ARTÉs RoMÁN \\ al260572@uji.es \\ LAURA LÓPEZ CRUZ \\ Icruz@uji.es \\ LIDÓN MONFERRER SALES \\ Imonferr@uji.es
}

\section{Resumen}

La detección de cambios en los niveles de un neurotransmisor, como la dopamina o de su cascada metabotrópica que se inicia con la activación de sus receptores tras la realización de una conducta o un tratamiento farmacológico en estructuras cerebrales concretas, puede ser realizada con técnicas inmunológicas. Los métodos inmunoquímicos en general se fundamentan en la utilización de anticuerpos específicos para el marcaje de una proteína concreta. En el caso de que se quiera localizar la proteína en áreas o neuronas concretas por inmunohistología, los anticuerpos unidos a enzimas (peroxidasa o fosfatasa) o a fluorocromos aplicados a cortes histológicos de cerebro, se unen a la proteína antigénica de interés permitiendo su marcaje mediante una reacción colorimétrica o emisión de fluorescencia, respectivamente. Esta técnica nos ofrece la oportunidad de realizar un mapeado cerebral y observar en qué regiones la proteína de interés está presente y en qué medida. Por ejemplo, se han utilizado estas técnicas para el marcaje y/o cuantificación de algunos marcadores dopaminérgicos, como el DARPP-32, en el núcleo accumbens. Además, esa proteína puede ser cuantificada mediante la técnica western blot (WB). EI WB requiere de la homogeneización del tejido, desnaturalización de proteínas y su separación por peso molecular mediante electroforesis y da como resultado una reacción quimioluminiscente detectable por una película fotográfica. Ambas técnicas son complementarias, pues ofrecen información de localización y permiten cuantificar la proteína.

Palabras clave: western blot, DARPP-32, inmunohistoquímica, dopamina.

\section{Abstract}

Detecting changes in the levels of a neurotransmitter such as dopamine or changes in the metabotropic cascade initiated by the activation of its receptors in specific brain structures after performing a behavior or receiving a specific drug therapy, can be accomplished with immunological techniques. Immunochemical methods are based on 
the affinity of antibodies for a particular protein. The antibodies are bound to a marker that provides color or fluorescence. In the immunohistological methods, after the antibody is applied to a specific brain section where the antigenic protein is localized, neurons containing the targeted protein show the color or fluorescence, and they can be identified and quantified by microscopy and imaging processing techniques. For example, these techniques have been used for the localization and quantification of some dopaminergic markers such as DARPP-32, in the nucleus accumbens. This protein can be quantified also by western blotting (WB). The WB requires tissue homogenization, protein denaturalization and separation of proteins by molecular weight with electrophoresis, and results in a detectable chemiluminescent reaction by an X-ray film. Both techniques complement each other providing information about localization, as well as quantity of protein present in the tissue.

Keywords: western blot, DARPP-32, immunochemistry, dopamine.

\section{Introducción}

Las técnicas histológicas permiten obtener información anatómica sobre los detalles de una zona concreta del cerebro con el fin de determinar diversos objetivos. Para realizar un análisis histológico de un tejido se llevan a cabo varios procesos (Patel y Aria, 1995), cuyo objetivo final es facilitar la visualización de los componentes de esa parte del tejido.

La detección de ciertas moléculas, puede utilizarse para determinar la composición química de las neuronas y así describir el tipo neuronal que compone un núcleo concreto. También puede utilizarse como un índice de activación neuronal y puede ayudarnos a la localización de sistemas funcionales. Los ensayos bioquímicos están dirigidos a detectar sustancias concretas basándose en las interacciones antígeno-anticuerpo. Existe una gran variedad de métodos derivados de esta propiedad que utilizan diferentes tipos de detección: por radioactividad, colorimetría o fluorescencia.

Los métodos inmunohistoquímicos se fundamentan en el uso de anticuerpos para la detección de una proteína concreta con la finalidad de obtener con precisión la distribución de ésta en el sistema nervioso o cualquier tejido. Los anticuerpos, que pueden estar unidos a un enzima que cataliza una reacción de color o directamente a una molécula fluorescente o radiactiva, son incubados en cortes histológicos de cerebro (o de otro tejido) de cualquier especie, pudiéndose observar su unión a la proteína antigénica en el tejido nervioso y poniendo así de relieve las zonas cerebrales que contienen la proteína estudiada (Watson y Cullinan, 1995).

El western blot y las técnicas de neurohistoquímica a menudo se utilizan para el marcaje de proteínas específicas en una región cerebral o para saber si en una neurona se ha traducido una determinada proteína. Estas técnicas pueden ser utilizadas independientemente o de manera complementaria según el objetivo a conseguir. Si la finalidad es saber qué cantidad de proteína existe en una determinada zona cerebral homogenada se puede utilizar el western blot. Si partimos de un tejido y el objetivo es la localización o mapeado cerebral de la presencia de una proteína específica, la inmunohistoquímica proporciona la posibilidad de visualizar, localizar y cuantificar dicha proteína.

El objetivo de este trabajo es estudiar ambas técnicas por separado, resaltando la idoneidad de utilizar una u otra. Además, se exponen los pasos en los que consisten cada una de las técnicas. Se tratará de saber el porqué y el cómo se realizan en un laboratorio. 


\section{Método}

La metodología neurohistoquímica comienza por la extracción del tejido. Con el objetivo de conservarlo y mantener intactas las proteínas de interés, se procede a la fijación. En este paso se conserva la morfología de las células, la organización química y su composición, alterándolas lo menos posible evitando su descomposición por bacterias o enzimas endógenas. El fijador utilizado más comúnmente es la formalina.

El siguiente paso consiste en el endurecimiento del tejido nervioso para darle consistencia y poder ser cortado. Se pueden utilizar distintos procedimientos, destacando la congelación del tejido o su inclusión en parafina.

Una vez endurecido, es posible realizar el corte del mismo en secciones muy finas para lo cual se utiliza el micrótomo que permite obtener secciones de un grosor controlado. El grosor del corte depende de la técnica que vaya a realizarse a posteriori. Por ejemplo, si el tejido se está preparando para su observación con microscopio óptico (de 10 a $100 \mu \mathrm{m}$ ) o electrónico $(1 \mu \mathrm{m})$.

Los tejidos una vez cortados son sometidos a lavados y se incuban con el anticuerpo primario. Una vez se ha incubado el anticuerpo primario, se realizan lavados para el exceso de anticuerpo que no haya sido adherido a los antígenos específicos. Hay que tener en cuenta que en la siguiente fase, se incuba el anticuerpo secundario y éste se unirá exclusivamente al anticuerpo primario. El anticuerpo secundario contiene un polímero de enzimas al que se unirá el cromógeno para poderse ver en microscopía (figura 1). El cromógeno más utilizado para este tipo de inmuhistoquímica es la di-amino-bencidina (DAB), que proporciona un color marrón cuando reacciona con las enzimas adheridas al anticuerpo secundario (figura 4, A y B).

Tras el marcaje de la proteína de interés puede realizarse la tinción del tejido solo en el caso de ser necesario. La tinción utilizada dependerá del tipo de células o estructuras celulares que se desee ver en el microscopio.

Los tejidos preparados mediante esta técnica pueden visualizarse con el microscopio óptico. Cuando estos microscopios se asocian a fotodetectores y sistemas informatizados de análisis de imagen, además de la visualización se hace posible la cuantificación. Puede utilizarse el microscopio electrónico de transmisión o el microscopio electrónico de barrido, que proporciona imágenes tridimensionales. En el caso de utilizar un fluorocromo adherido al anticuerpo secundario y la reacción final resultante fuera una reacción fluorescente se utilizaría un microscópio confocal para su visualización (figura 4, C y D).

Las técnicas inmunohistoquímicas comentadas nos permiten hacer un rastreo anatómico de en qué lugares y en qué neuronas se sintetiza más o menos una proteína determinada. Como por ejemplo la proteína DARPP-32. Sin embargo, si lo que queremos es cuantificar proteínas sin tener esta especificidad regional, el western blot (WB) puede darnos esa información.

El primer paso a realizar, al igual que en la inmunohistoquímica, es la extracción del área en cuestión. En este caso no se requieren de los procesos de fijación, inclusión y corte como en las técnicas inmunohistoquímicas, sino que se extrae el tejido en "fresco» y se selecciona el área a explorar. Posteriormente, la muestra se homogeneíza en un tampón de lisis que permite extraer las proteínas de interés del tejido, así como bloquear enzimas que podrían degradar la muestra. El homogenado resultante se centrifuga y se obtiene un sobrenadante en el que se encuentran las proteínas (figura 2). 


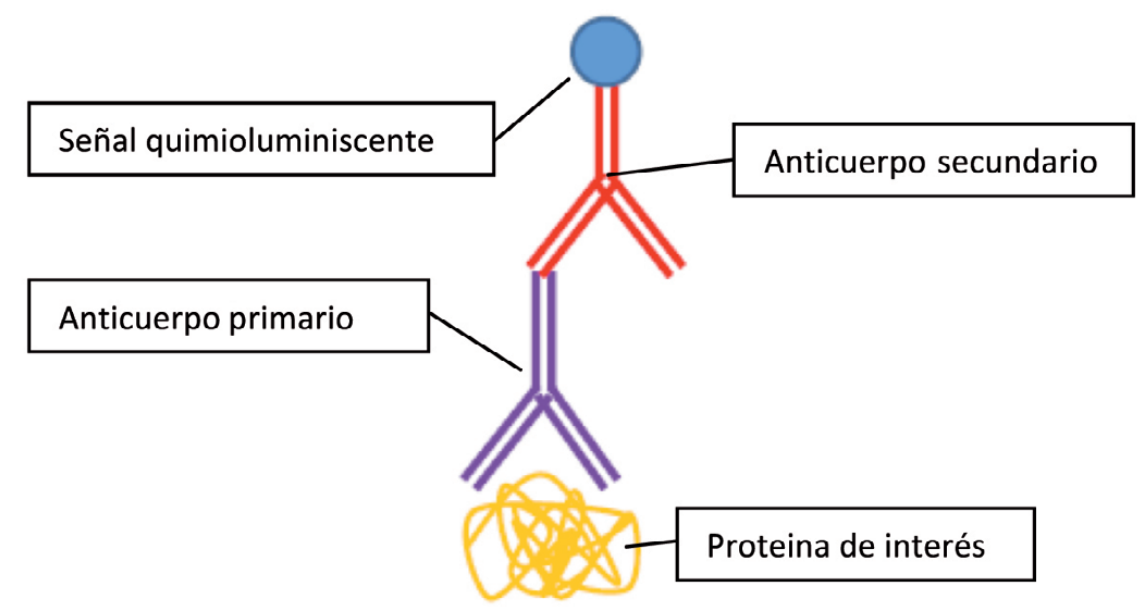

Figura 1. Incubación de Ac1 y Ac2 con señal quimioluminiscente o colorimétrica dependiendo de la técnica

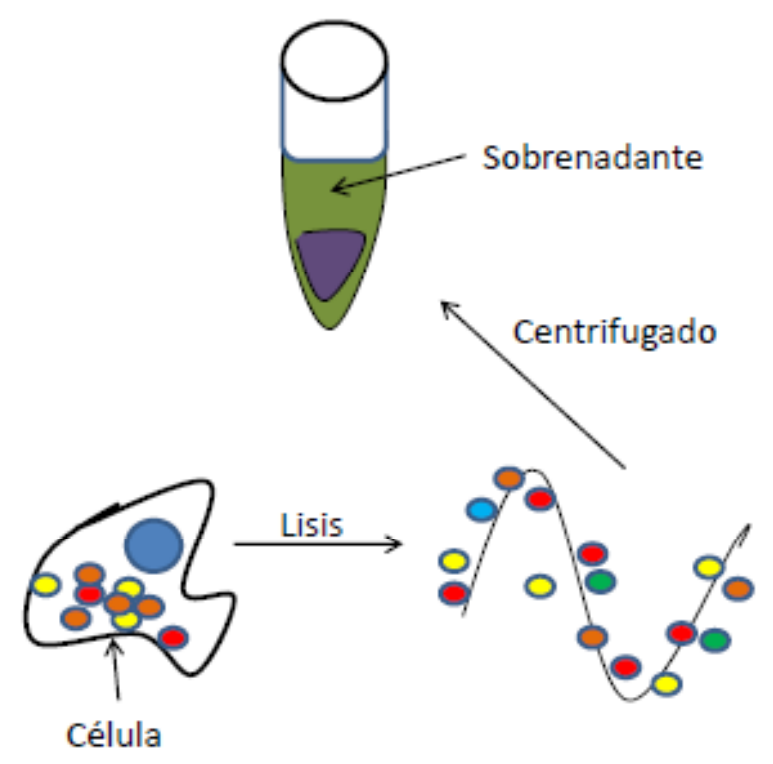

Figura 2. Homogeneización del tejido

Una vez homogenada la muestra, se cuantifican las concentraciones de las proteínas que cada una de nuestras muestras tiene. Este paso se realiza para conocer con qué cantidad de cada muestra deberemos trabajar para partir de muestras con cantidad de proteína equivalente. En esta fase se utiliza un espectrofotómetro y se emplea el método Bradford (1976).

Posteriormente, cada muestra es sometida a electroforesis. En esta fase es necesario un tampón de carga y un gel de acrilamida entre otros muchos componentes. Cada una de las muestras se vierte de forma controlada dentro del gel que gracias a su composición contiene unos poros que permiten el paso de las proteínas haciendo que éstas se ordenen por su peso molecular. De este modo, las moléculas más grandes se quedarán en lugares más ascendentes $\mathrm{y}$, por el contrario, las más pequeñas, llegarán al fondo. El movimiento y la separación de las proteínas por el gel se consigue otorgándoles una carga negativa (al mezclarlas con el 
tampón de carga) y aplicándoles una corriente eléctrica. En el extremo superior del gel se sitúa el ánodo y en el inferior el cátodo. De esta manera, las proteínas cargadas de forma negativa y cada una de ellas con un peso molecular diferente se desplazarán hacia abajo atraídas por la fuerza del cátodo (figura 3).

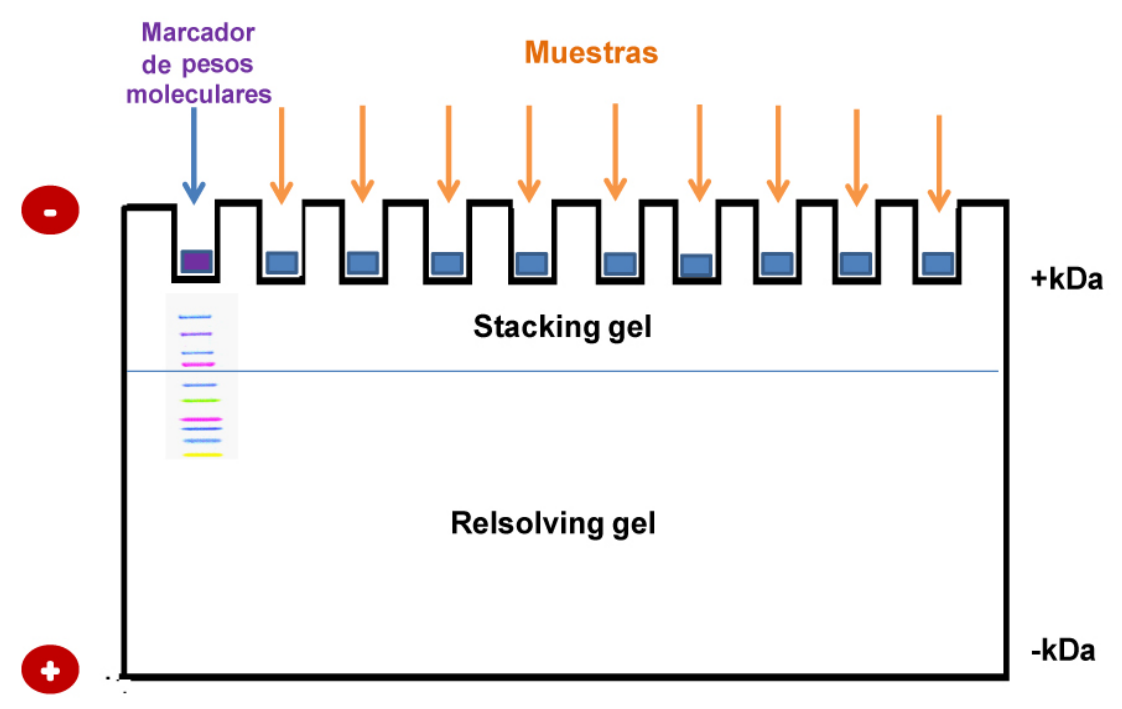

Figura 3. Electroforesis

Tras la electroforesis las proteínas se habrán separado en filas dependiendo del peso molecular. Gracias a que nuestra proteína de interés tiene un peso molecular conocido (por ejemplo, $32 \mathrm{kDa}$ en el caso de la proteína DARPP-32), y a que junto a las muestras hemos introducido un marcador de pesos moleculares (que nos sirve de guía para saber la localización de proteínas de diferente peso por el gel), podemos saber en qué parte del gel se sitúan nuestras proteínas de interés.

Una vez localizada nuestra proteína de interés en el gel, se realiza la transferencia con la finalidad de darle a las proteínas un soporte sólido en el que situarse. La transferencia consiste en el paso de las proteínas del gel a una membrana de nitrocelulosa o PVDF. A partir de aquí, el proceso se asemeja a la de la inmunohistoquímica en tanto que se realizan los bloqueos de inespecificidades, se incuba el anticuerpo primario, se realizan sucesivos lavados y se incuba el secundario. Sin embargo, para la detección y visualización de las proteinas, la reacción final es una reacción inmunoluminescente. El anticuerpo secundario está adherido a un enzima de peroxidasa de rábano (HR; horseradish peroxidase). Estas proteínas reaccionan con un sustrato quiminoluminescente (ECL) produciendo una reacción luminosa (figura 1). De esta manera las proteínas de interés, detectadas por la cadena anticuerpo primario-anticuerpo secundario$\mathrm{HR}$, se visualizan como bandas luminosas.

Con el objetivo de cuantificar estas bandas luminosas se procede al revelado mediante papel fotográfico, en el que revelarán las bandas, obteniendo un patrón de manchas oscuras. La intensidad de estas marcas será indicativa de la cantidad de proteína de interés que hay en una de las muestras con las que hemos trabajado. A diferencia de las técnicas inmunohistoquímicas, no se precisará de microscopia para su visualización. De esta manera, siguiendo con los 
ejemplos de marcadores dopaminérgicos, sabremos si ante una manipulación determinada, la síntesis de proteína DARPP-32 se ve incrementada o reducida, en comparación con otras manipulaciones en una región cerebral concreta (figura 5).

\section{Resultados}

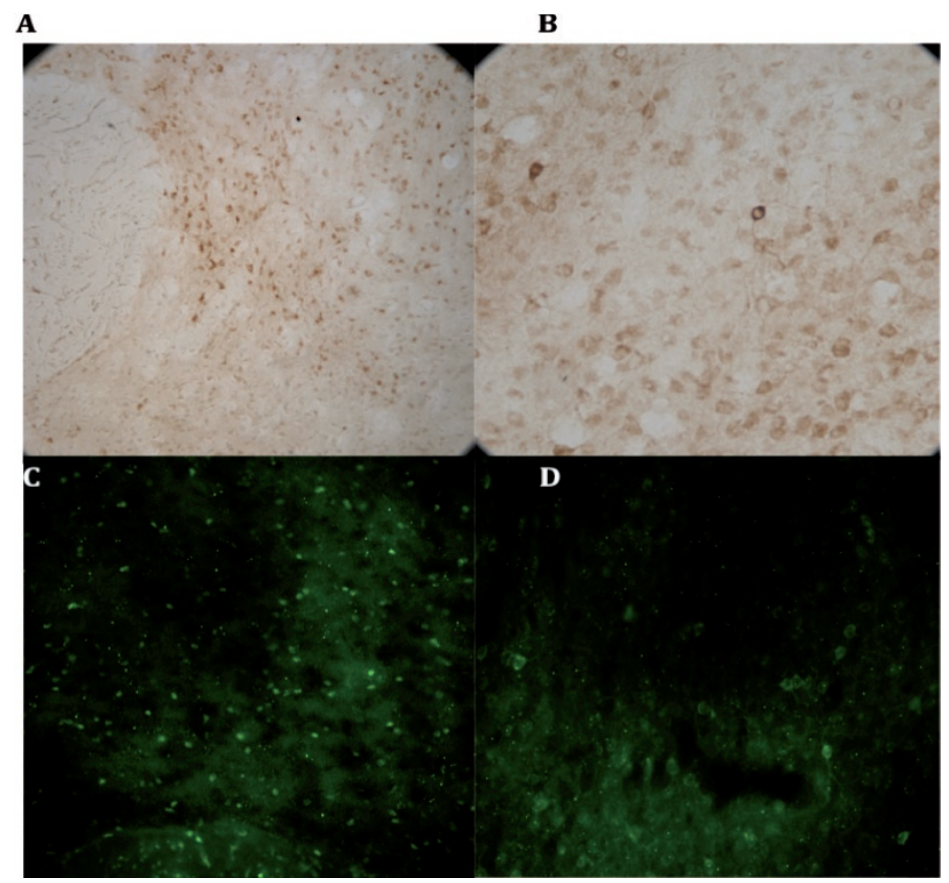

Figura 4. Marcaje de DARPP-32 en el núcleo accumbens core mediante inmunohistoquímica en animal que ha recibido antagonista dopaminérgico. A y B, marcaje con color; B y C, marcaje con fluorescencia.

Fotos tomadas con objetivo 40X. (Randall y cols., 2012, 2014)

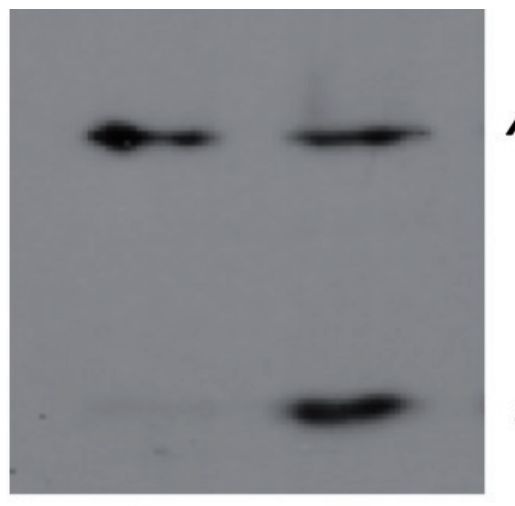

\section{Actina (42Kd)}

$\mathbf{A}$

B

Figura 5. Cuantificación de DARPP-32 en el estriado mediante western blot. A) muestra procedente del animal control, B) muestra procedente de animal tratado con depletor dopaminérgico (López-Cruz y cols., 2015) 


\section{Discusión y conclusiones}

Mediante la inmunohistoquímica se identifican las neuronas en las cuales se ha marcado la proteína de interés. Ésta, a su vez, se puede cuantificar mediante la visualización al microscopio gracias a la reacción final, colora (figura 4, A y B) o fluorescente (figura 4, C y D). Ello permite identificar áreas cerebrales muy concretas donde la proteína se ha sintetizado. Sin embargo, la cuantificación no alude a la cantidad de proteínas sino a la cantidad de neuronas que la han expresado.

EI WB es una técnica que se utiliza para la cuantificación de proteínas específicas que se expresen en un tejido concreto, en este caso el DARPP-32 (figura 5). No obstante, la localización es menos precisa, ya que se utiliza una muestra cerebral de una región concreta homogeneizada.

En la práctica, resulta igual de importante tanto saber qué cantidad de proteína se ha expresado como indicar la región cerebral en cuestión. Por ello, pueden utilizarse ambas técnicas como complementarias.

\section{Referencias}

Bradford, M. M. (1976). A rapid and sensitive method for the quantitation of microgram quantities of protein utilizing the principle of protein-dye binding. Analytical Biochemistry, 72, 248-54.

López-Cruz, L., San Miguel, N., Carratalá, C., Monferrer, L., Correa, M. y Salamone J. D. (2015, julio). Shift from activity-based to sedentary sources of reward in a decision making task for mice: dopamine depletion and adenosine antagonism en el Primer Congreso Internacional de Psicobiología, Oviedo, España.

Patel H. R. y Arya, M. (2007). Inmunohistochemistry. Basic science techniques in clinical practise. (pp. 18-31). Londres: Springer.

Randall, P. A., Lee, C. A., Podurgiel, S. J., Hart, E., Yohn, S. E., Jones, M., ... y Salamone, J. D. (2014). Bupropion increases selection of high effort activity in rats tested on a progressive ratio/chow feeding choice procedure: implications for treatment of effort-related motivational symptoms. The International Journal of Neuropsychopharmacology, 18(2). doi: 10.1093/ijnp/pyu017.

Randall, P. A., Pardo, M., Nunes, E. J., López-Cruz, L., Vemuri, V. K., Makriyannis, A., ... y Salamone, J. D. (2012). Dopaminergic modulation of effort-related choice behavior as assessed by a progressive ratio chow feeding choice task: Pharmacological studies and the role of individual differences. PLOS ONE, 7, e47934.

Watson, S. T. y William, E. C. (2000) Cytology and Circuitry. Psychopharmacology - 4th Generation of Progress, http://www.acnp.org/g4/GN401000003/Default.htm. 